\title{
An Exploratory Cross-Sectional Survey Study of Elementary Teachers' Conceptions and Methods of STEM Integration
}

\author{
Kathryn "Annie Arnone" a1, Deborah Hanuscin” \\ ${ }^{a}$ Endeavor STEM Education, USA; ${ }^{b}$ Western Washington University, USA
}

\begin{abstract}
Because elementary teachers are typically responsible for teaching all subjects, there is a unique opportunity for integrative approaches to teaching iSTEM Education at the elementary level (Becker \& Park, 2011). However, there is a need for professional development if teachers are to be successful in teaching iSTEM Education (NRC, 2011), as elementary teachers may lack strong content knowledge in STEM disciplines (Ginns \& Watters, 1995; Trygstad, 2013; Honey et al., 2014; Fulp, 2002; Ma, 1999; Hanover, 2012). Elementary teachers are prepared as generalists--they take few courses in STEM content, and experiences with iSTEM Education in their teacher preparation programs are rare (Fulp, 2002). Beyond the need for professional development related to STEM content knowledge, however, we know very little about the unique needs of elementary teachers regarding instructional approaches to iSTEM Education. This study examines and describes the ways in which elementary teachers conceptualize iSTEM Education and the integrative approaches they use when teaching STEM content, with the intent to inform the development of elementary specific iSTEM Education professional development.
\end{abstract}

Keywords: STEM, integration, iSTEM, integrated STEM, elementary STEM

\section{Introduction}

According to the President's Council of Advisors on Science and Technology (2010), "the success of the United States in the 21st century will depend on the ideas and skills of its population" (p. 5). Science, Technology, Engineering, and Mathematics (STEM) Education works to develop students who have the technical skill-set necessary to boost the United States back into the global economic competition (PCAST, 2010). While STEM Education lacks a formal, universally accepted definition, there is an overwhelming consensus regarding the importance of the need to develop STEM literate individuals. Trygstad (2013) stated "A new workforce of problem-solvers, innovators, and inventors who are self-reliant and able to think logically is one of the critical foundations that drive innovative capacity" (p. 1). These national reform documents all call for increased STEM curricula and instruction to increase the number of students going into STEM fields (Ring et al., 2017) and elementary teachers are on the front lines in tackling the challenge.

To address the need for STEM literate individuals, elementary teachers have been charged with building the foundation for this STEM workforce. However, there is little research that can inform the design of iSTEM professional development to address the unique challenges elementary teachers face when teaching iSTEM Education. The findings from the exploratory cross-sectional survey study intend to describe current conceptions and practices of elementary teachers in order to provide insight into the unique professional development needs of elementary teachers in iSTEM Education.

${ }^{1}$ Corresponding author. Endeavor STEM Education, Contact: 573-310-1013, E-mail: karnone@us-satellite.net 


\section{Review of Relevant Literature}

The present study is informed by literature related to defining STEM, integrating STEM, and preparing teachers to implement STEM.

\section{Defining STEM Education}

Despite the consensus among the education community regarding the importance of STEM Education, there isn't a universal consensus on a definition (Shernoff et al., 2017), or agreement that one is needed. A simple search in the literature for STEM Education yields an array of varying ideas for defining STEM. When comparing these definitions, several patterns emerge. First, STEM Education is conceptualized in three distinct ways-- as an approach to learning, as an approach to teaching, and as a philosophical stance toward education. Across these three distinctions, however, there are some commonalities. For example, the need for providing opportunities for students to apply their knowledge is prevalent among many definitions, as well as the focus on integration.

Integrative approaches are defined as "approaches that explore teaching and learning between/among any two or more of the STEM subject areas, and/or between a STEM subject and one or more other school subjects (Sanders, 2009, p. 21)." Proponents of iSTEM Education agree that an integrative approach is a key component of effective iSTEM Education instruction (Johnson et al., 2015; Nadelson et al., 2013); but there is no consensus among the education community regarding the method of integration (Means et al., 2008), and there are a variety of ways in which STEM content can be integrated (Becker \& Park, 2011). Furthermore, there are varying depths by which STEM content can be integrated (Nathan et al., 2013) and there are empirical studies supporting the use of curriculum that promotes integrated STEM Education experiences (Wang, et al., 2011). The current literature, however, focuses primarily on the integration of math and science, rather than on integration across all STEM disciplines (Heil et al., 2013).

\section{Preparing Elementary Teachers to Integrate STEM}

Elementary classrooms have different affordances for integration than secondary educators as there is flexibility in the elementary curriculum that can support new approaches for teaching iSTEM Education (Nadelson et al., 2013). Furthermore, elementary teachers are typically responsible for teaching all subjects, so there is a unique opportunity for integrative approaches to teaching iSTEM Education at the elementary level (Becker \& Park, 2011). Yet, there are few elementary specific iSTEM Education professional development opportunities (as opposed to specific to individual disciplines of STEM) (Hanover, 2012). Both research and professional development on iSTEM Education are often grouped together in a K12 bundle and don't distinguish between the levels of elementary or secondary education (Hanover, 2012) where the affordances for integration are quite different.

\section{Need for the Study}

Though the elementary classroom presents unique affordances for iSTEM Education, we currently know very little about how elementary teachers conceptualize iSTEM, which types of integration elementary teachers are using in their instructional approaches to iSTEM Education, and the unique needs that elementary teachers may have when it comes to iSTEM Education professional development. Considering teacher beliefs and perceptions regarding integrative approaches among STEM content as teacher professional development programs work to develop teacher thinking and practice is important as both teacher attitudes and perceptions "drive classroom actions and influence the teacher change process" (Richardson, 1996, p. 102). To address the gaps in the literature revealed above, this study examines the conceptions and integrative practices of elementary teachers in iSTEM Education and explores difficulties elementary teachers face when teaching iSTEM Education that can shed light on their specific professional development needs. 


\section{Theoretical Framework Guiding the Study}

This study is framed by the iSTEM Education framework by Honey and colleagues in the report STEM Integration in K-12 Education: Status, Prospects and an Agenda for Research (2014). This framework includes four main features: (a) goals of integrated STEM Education, (b) outcomes of integrated STEM Education, (c) the nature and scope of integrated STEM Education, and (d) implementation of integrated STEM Education (p. 31). This framework is intended to provide researchers with the vocabulary to "identify, describe, and investigate specific integrative STEM initiatives..." (Honey et al., 2014, p. 31).

The present study also uses the integration approaches described by Davison, Miller, and Metheny (1995) as an analytical framework. Davison et al. (1995) described five types of integration specifically related to math and science. However, this framework can easily be applied to STEM disciplines more broadly. These five methods include: (a) Discipline Specific Integration (b) Content Specific Integration (c) Process Integration (d) Methodological Integration and (e) Thematic Integration. Like many integrative models, however, these approaches are not grounded in studies of actual teachers' integrative practices but are merely presented as options for integration. Thus, the present study will provide an empirical test of the framework.

The study described in the following section is guided by the following research questions:

1. To what extent are elementary teachers' prepared to implement iSTEM Education?

- What are elementary teachers' perceived levels of preparedness to implement iSTEM Education?

- What is the nature of iSTEM Education opportunities in which elementary teachers have participated?

2. In what ways do elementary teachers approach iSTEM Education in their lesson plans?

3. How do elementary teachers conceptualize iSTEM Education?

- What learning goals do elementary teachers have for students as part of their iSTEM Education lessons?

- What do teachers see as the benefits of students learning about iSTEM Education (outcomes)?

- What is the nature and scope of teachers' integration of STEM disciplines?

- What instructional designs, supports, and adjustments to the learning environment do teachers utilize when integrating STEM content?

\section{Methodology}

This qualitative study used an exploratory cross- sectional survey design to examine the variations in the ways elementary teachers conceptualize and design iSTEM Education instruction. A cross-sectional survey approach was appropriate for this study as I intended to reveal the conceptualizations and practices of elementary teachers regarding iSTEM Education at a single point in time (Creswell, 2013). An exploratory study was appropriate because of the lack of detailed preliminary research in this area and because I desired to show that further research is needed (Stake, 1995). The intent is to provide insight into teachers' conceptions that can inform further research in iSTEM Education, specifically in regards to the unique professional development needs of elementary teachers. 


\section{Context of the Study}

\section{Participants}

Participants in this study were certified classroom elementary teachers in a Midwestern state. Participants were collected using a convenience sample and snowball sampling via email, social media, internet postings, and word of mouth. Twenty-nine teachers responded initially, submitting responses to an online survey as well as an iSTEM Education lesson plan. The twenty-nine teacher participants in this study taught grades Kindergarten through 5th grade. 38\% taught Kindergarten through second grade, while 62\% taught third through fifth grade. $45 \%$ of teachers taught in an urban area while $55 \%$ taught in a rural area. $27 \%$ of teachers had 1-5 years teaching experience, $28 \%$ had $6-10,28 \%$ had $11-15$, and $17 \%$ had 16 or more years of teaching experience.

\section{Data Sources and Analysis}

The data collected included a survey, an iSTEM Education lesson plan, and an interview. Research questions 1 and 2 were answered by examining survey and lesson plan data for the entire sample, whereas research question 3 was answered by interviewing a purposeful subsample of participants in-depth.

\section{Survey}

Stage one of data collection for this study began with a Teacher Survey. The intent of this survey was to reveal the teachers' ideas regarding iSTEM Education, their level of teaching experience in general and specific to iSTEM Education, and the types of professional development experiences teachers have had related to iSTEM Education. The survey included demographics and questions that addressed the instructional resources they use and the professional development they have had specifically related to STEM Education. Responses to the survey questions assisted in determining where the teacher would fall on the beginner to expert continuum and was used to help select cases for the purposeful sample.

All teachers in the population sample completed a teacher survey using the Jotform online survey tool. Teacher participants were categorized into groups based on their responses to survey questions to provide insight on the range of experience and knowledge in iSTEM Education of the population sample. I then analyzed each survey by identifying which ones included the themes that best addressed the research questions for this study. After careful review of the survey results, directed content analysis was conducted to determine the frequency of concepts and ideas that arose in the data (Petocz \& Newbery, 2010) and to determine a purposeful sample to interview.

\section{iSTEM Education Lesson Plan}

Lesson plans are essential forms of data as they reflect outcomes teachers have for their instruction and were chosen for this study as there was a desire to learn more about teacher instructional practices (Sias et al., 2016). Lesson plan submission requirements were as follows a) the lesson must be a lesson the teacher has previously taught $b$ ) the lesson is written by the teacher (i.e. not a scanned copy of a lesson included in a curriculum book, though teachers may draw on lessons created by others) and c) the submission includes all additional items (worksheets, rubrics, etc.). While not all teachers may have experience in creating iSTEM lesson plans specifically, they all should have had experience with creating lesson plans for their classroom. These iSTEM Education lesson plans were intended to provide an example of the extent to which these teachers are integrating STEM content in their iSTEM Education lesson designs, and helped determine which participants should be interviewed in Stage 2 of the data collection process.

Lessons were then sorted by integration methods following Davison and colleagues' (1995) five types of integration (a) Discipline Specific Integration, (b) Content Specific Integration, (c) Process Integration, (d) Methodological Integration and (e) Thematic Integration. Each lesson was sorted based on the information provided in the lesson plan. A few issues arose as not all lessons included exactly the same elements as no general lesson plan template was provided. Teachers were allowed to submit lessons in whichever way they 
desired. Assumptions were made at times as to what subjects were being used as no standards or objectives were explicitly written. Some lessons also claimed to include elements such as engineering, but upon further analysis, it was found that they did not.

\section{Interviews}

Five teachers were chosen as the purposeful sample and all participated in a follow-up phone interview, allowing for further clarification of instructional choices as well as descriptions of conceptualizations and teaching practice. These teachers were chosen as they all used a different integrative approach in their iSTEM Education Lesson Plan and represented a range in multiple categories (grade level taught, years of teaching experience, experience in STEM, etc.). In this manner, their responses could illustrate the range of ways in which teachers conceptualize iSTEM education across a variety of integrative approaches.

Integration methods used in iSTEM Education lesson plan submissions of the purposeful sample included Methodological Integration, Thematic Integration, Content Specific Integration, Process Specific Integration, and No Integration. This subset of teachers was chosen to better understand the range and types of integration used by elementary teachers when designing iSTEM Education instruction.

All interviews were transcribed for analysis, which began with open-coding of hard copies of the transcripts. A highlighter color was assigned for each of the research questions, and transcripts were examined line-by-line to identify excerpts relevant to each question and assign codes. Intercoder agreement was established through analysis of a sample of data conducted by myself and a peer debriefer. Using the Teacher Interview responses to the question "Why is it important for students to learn STEM?" the peer debriefer and I used open coding for first-level coding and then directed content analysis with axial coding for second-level coding, to independently read and code themes by hand. These themes were both predetermined (integrative approaches in the iSTEM lesson plans) and those that emerged from the data (in all data sources). We then came together to compare codes and themes to check for intercoder agreement. Any differences were discussed, and changes in coding were made as agreed upon by coders.

Once coding was complete, codes for each research question were entered into an Excel workbook with a separate tab for each question/code set. Frequencies of codes across all five participants were noted to assess the prevalence of the codes across the entire data set. Codes were then grouped into categories based on similarities and themes that emerged. Themes were then examined in relation to the research questions, and the absence of particular themes was also noted.

\section{Results}

The results are presented in order of the research questions, beginning with information about elementary teachers' preparedness to implement iSTEM, the methods by which they approach STEM integration in their lessons, and how they conceptualize iSTEM education. Results should be interpreted within the limitations of this study, which include the small sample size of teacher participants. Teachers were self-selected, and it is possible that teachers who chose to participate in the study are biased and are more "pro-STEM" than their colleagues who were not involved in the study. Additionally, the sample is limited to elementary teachers in one state, and the findings of this study may not apply to all elementary teachers.

\section{Experience Level with STEM}

First, teachers self-placed themselves on a STEM Education experience continuum describing their previous work in STEM Education that ranged from Beginner to Advanced. 69\% identified as Beginners, 11\% identified as Somewhat Experienced, 17\% identified as Experienced, 3\% identified as Somewhat Advanced, and $0 \%$ identified as Advanced. Placements on the continuum were intended to provide a ranking of teacher participants in regard to their current experience in STEM Education. These self-rankings were not necessarily made based on similar understandings of 'STEM Education', and some teacher participant placements did not 
necessarily match their actual level of experience, based on the analysis of their lesson and interview. During interviews, some teacher participants who identified themselves at a higher level of experience ended up indicating they would change their ranking to a lower level. Regardless of the actual accuracy of continuum placements by teacher participants, these "rankings" allowed us to see where teachers thought they were on the STEM Education experience continuum, based on the way they conceptualized iSTEM Education at the time.

\section{Participation in STEM Professional Development}

Next, teachers reported on the hours of professional development they have experienced in the past two years related to STEM Education. 38\% reported 0 hours, 38\% reported 1-25 hours, 10\% reported 26-50 hours, $4 \%$ reported 51-100 hours, and 10\% reported more than 101 hours. Of the professional development hours reported, teachers identified the number of those hours that were elementary specific experiences versus those that were presented in a K12 bundle. 38\% identified 0 hours of elementary specific STEM professional development, $41 \%$ identified $1-25$ hours, $10 \%$ identified $26-50,4 \%$ identified $51-100$, and $7 \%$ identified more than 101 hours of elementary specific professional development.

The majority of elementary teachers in this study have not participated in many hours of STEM related professional development. Some teachers who did report higher amounts of STEM-related professional developed, mentioned that they considered individual subject area professional development experiences (science, technology, or math professional development) as part of their hours of STEM-related professional development, even though the experience did not focus on integrated STEM Education.

Teachers were also asked to rate their satisfaction with the STEM Education professional development they had attended over the past two years. 27\% were Not Satisfied, 14\% were Somewhat Satisfied, $45 \%$ were Satisfied, and $14 \%$ were Very Satisfied. Some teachers indicated they were satisfied with the STEM Education professional development they had attended, even though they had reported attending zero hours of STEM Education specific professional development. Teachers who expressed this stance towards STEM Education professional development were generally not concerned with the fact they hadn't had any specific STEM professional development. They were either uninterested in receiving professional development in STEM Education or they expressed that they were unaware that they needed it.

Finally, teachers rated their satisfaction with the availability of STEM Education professional development. 45\% were Not Satisfied, 7\% were Somewhat Satisfied, $41 \%$ were Satisfied, and 7\% were Very Satisfied. Some teachers indicated they might get more STEM Education professional development if they asked their district, but they were unaware of any opportunities that were readily available to them.

Many participants in this study were mostly satisfied (45\%) with the STEM Education professional development they attended, but most (45\%) were unsatisfied with its availability. While participants expressed a general satisfaction with the STEM Education professional development they had attended, the specific nature of those experiences are unclear. Interviews with a sample of participants was intended to provide more detailed information about teachers' satisfaction with the quality and availability of STEM PD opportunities.

\section{Teachers' Approaches to Integrating STEM}

Analysis of teachers' lessons revealed a wide variety of conceptions, and approaches to STEM education. Considering the Six Essential Features of Effective STEM Integration (Johnson et al., 2015), teachers in this study did not include and were not primarily concerned with the majority of the features considered to be essential.

For example, meaningful learning and engaging contexts (feature 1) was either not included or was surface level. Engineering design challenges were almost missing entirely (feature 2) and explicit standards addressed in lessons (feature 4) specific to math and science were weak or missing. Finally, most teachers did not focus on providing learning experiences where students had the opportunity to deepen their conceptual knowledge (feature 5). Teachers tended to address feature 3 (allowing mistakes) and feature 6 (collaboration) 
in their lesson plans.

An analysis of lessons using Davidson et al's framework also showed variation in how teachers integrated STEM. First, the majority of the lessons submitted from the population sample (48\%) fell into the category of No Integration; meaning the lesson was primarily one subject only. For example, one teacher submitted a lesson plan with the goal of students being able to identify area and perimeter of a square and a rectangle using a formula. Math was the only subject represented.

The next largest proportion (21\%) of teachers submitted lesson plans that were Process Integration; meaning they posed a problem and used science processes and math standards to find answers. For example, one teacher submitted a lesson plan that asked students construct a bridge out of toothpicks and gum drops. Students create and record multiple types of bridges, focusing on which shapes of bridges could hold the most weight. Students test and collect data to ultimately try and determine which shape bridge is best for holding the most weight.

The third largest proportion (17\%) of teachers submitted lesson plans that used Content Specific Integration; meaning they used at least one standard from one subject and another standard from another subject. For example, one teacher submitted a lesson plan using one standard from science and one standard from math. This lesson had students investigating friction by pulling water bottles attached to spring scales across various surfaces and calculating the averages of multiple pulls across each surface in Newtons.

The two smallest categories were Thematic Integration and Methodological Integration. Only 7\% of teachers submitted lesson plans that used Thematic Integration; meaning all content areas focused on a theme. For example, one teacher used "pumpkins" as the theme of her lesson, and included activities such as estimating the number of pumpkin seeds inside the pumpkin, painting the pumpkin, and reading and writing stories about pumpkins. Only 7\% of teachers submitted lesson plans that were Methodological Integration; meaning they used inquiry, the learning cycle, discovery, etc. to build knowledge using science and math. For example, one teacher submitted a lesson plan that used the $5 \mathrm{E}$ learning cycle where students used science, engineering, and math to learn about the water cycle. Students progressed through each learning sequence, engaging in activities that helped them discover how the water cycle works and then progressed into designing solutions to solve water pollution problems.

No teachers $(0 \%)$ submitted lessons that were Discipline Specific Integration; meaning they pulled standards/content from different fields in the same subject (i.e. Algebra and Geometry or Biology and Geology). That is, teachers typically stuck to a specific topic within a discipline, as opposed to focusing on cross-cutting concepts within a discipline.

Interviews with the purposeful sample of teachers sheds light on the nature and scope of teachers' integration within each category, the learning goals they defined for students, their perceived benefits of teaching STEM, and how they conceptualize and enact STEM. These data are presented in the form of vignettes (see Appendix A) describing the teacher participants and the integrative approach their iSTEM Education Lesson Plans used.

\section{Discussion}

The purpose of this study was to examine and describe the ways in which elementary teachers conceptualize iSTEM Education and the integrative approaches they use when teaching STEM content, with the intent to inform the development of elementary specific iSTEM Education professional development. The findings of this study are discussed in light of the research questions in the sections that follow. 


\section{To what extent are elementary teachers prepared to implement iSTEM Education?}

Teachers in this study were generally unprepared to implement iSTEM Education, as evident by the lack of STEM Education specific professional development attended as reported by teacher participants. This is not surprising considering that elementary teachers lack content knowledge in STEM content areas (Trygstad, 2013; Honey et al., 2014; Fulp, 2002; Ma, 1999; Hanover, 2012) and receive little preparation in these areas during their teacher preparation programs (Fulp, 2002).

An area that is surprising among the data, is how elementary teachers are seeking out iSTEM Education opportunities and materials on their own due to the lack of support in the area provided by their school or district. Some teachers are using their personal resources to learn how to teach iSTEM Education by writing grants and attending conferences, while others rely solely on those experiences provided by their district or what they can find on the internet. Furthermore, the experiences provided by the districts related to iSTEM Education, tend to be focused on individual subject-specific resources with "STEM" iPad applications and websites used to enhance a lesson. This plays into the idea that iSTEM Education, like technology (Williams, 2011), is being used as a tool to enhance other subjects, rather than a subject of its own.

To some in the study, iSTEM Education is just another "thing" that teachers are required to learn about, but has little effect on their daily teaching practice. However, to others, iSTEM Education is meaningful and they desire assistance in learning how to adjust and modify their teaching practice in a way that is reflective of effective iSTEM Education.

In what ways do elementary teachers approach iSTEM Education in their lesson plans?

Teachers in this study struggled with how to approach designing iSTEM Education lesson plans. Lesson plans were vague, underdeveloped, scattered, or inappropriate for teaching the desired objective. This is possibly indicative of how much time in general elementary teachers are spending on iSTEM Education. They aren't devoting much time in the classroom to iSTEM Education so they aren't taking the time it takes to develop quality iSTEM Education lessons. The reasons why could be numerous and each participant may fall into more than one category.

Perhaps teachers submitted these types of lesson plans because they didn't have time to find anything else. Most teachers reported the lessons they submitted were pre-made so teachers weren't developing them from scratch for this study. Many also reported using websites where they could quickly find a lesson and use it in their classroom.

Perhaps teachers submitted these types of lesson plans because they truly don't know how to integrate and this was their best guess. It is interesting to consider how representative these lessons are of elementary teachers' understanding and ability to create iSTEM Education lessons. For example, teachers indicated that math was difficult to integrate and very few of them submitted lesson plans that integrated math. When teachers did try to integrate, some of their lessons included more standards and objectives than what would seem feasible for moving students towards mastery.

Finally, perhaps teachers submitted these types of lesson plans because they really did represent the way they conceptualized iSTEM Education at that particular moment. Teachers in this study focused on student engagement and making learning fun for their students so many of their lessons focused on being fun and engaging without a focus on content.

\section{How do elementary teachers conceptualize iSTEM Education?}

Teachers in this study appear to have general ideas regarding their role as the teacher when teaching iSTEM Education. Teachers see themselves as guides or facilitators and focus on making sure they give their students some independence in their learning. However, these ideas are underdeveloped, and there is a much larger emphasis on students being independent and self-guided than there is on content mastery. 
Second, there is little consensus among teachers regarding what is or should be taught in iSTEM Education. Some teachers felt a STEM lesson had to include all four subjects represented in the acronym (science, technology, engineering, and math) while others felt their STEM lesson could include all subjects. Additionally, the nature of the activities described by the teachers show differences in their overall approach to teaching iSTEM Education. For example, utilizing the teaching orientations as described by Magnusson, Krajcik, and Borko (1999), teachers showed multiple orientations to teaching iSTEM Education, but all of them fell into the categories of Activity Driven, Discovery, Project-based, and Guided Inquiry. Sidney and Cassie were primarily Activity Driven, though Cassie also had qualities of Discovery and Sidney had qualities of Project-based. Laura, Kim, and Mary were all primarily Guided Inquiry.

There is some consensus among teachers as to what students should be doing in iSTEM Education. Teachers expressed that students should be working with materials and participating in hands-on activities. Students should have opportunities to create, design, and build and their classroom environment should be such that students are okay with making mistakes.

Notably, teachers in this study differed in how they viewed technology as part of iSTEM Education. Teachers, for the most part, did not express ideas about technology in ways beyond using instructional technology (iPads and other electronic devices). Some teachers commented that they were aware that technology didn't have to be an electronic device. However, their representation of technology in their interviews and lesson plans expressed their dependency on electronic devices and "gadgets" to satisfy their technology integration. Most teachers used technology as a tool to enhance STEM lessons as opposed to focusing on specific technology skills or concepts.

Teachers also fluctuated on their understanding of the STEM acronym. Some understood the acronym to be STEM while others were adamant it was (or believed it should be) STEAM, integrating the Arts into the acronym. Not surprisingly, another area of mismatch appears when comparing teachers' definitions of STEM Education. Just like the rest of the education community, there was no consensus among teachers in the study regarding what STEM Education is and is not. Teachers had ideas, but most were underdeveloped, misguided or incomplete.

What learning goals do elementary teachers have for students as part of their iSTEM Education lessons?

The primary goal teachers expressed for their iSTEM Education lessons was problem-solving. Teachers commented on how students needed to be able to be good problem solvers for future careers and everyday life. Teachers felt problem-solving was important, regardless of whether or not the problem was authentic or contrived. Teachers also had a strong desire to use iSTEM Education as a way to teach students to be independent and self-guided. Additionally, teachers placed a large amount of importance on using iSTEM Education to boost student communication skills through collaboration, team building, and sharing of ideas. Some teachers described their use of iSTEM Education lessons as primarily "ice breakers" or "fillers" when they had a little extra time to "do something fun." Teachers had no concern about meeting standards or objectives during these lessons but rather desired their students to get to know each other and learn to work together and share their ideas.

Building on the previous idea, few teachers had an overall concern about mastery of content or skills as a learning goal. Teachers were more concerned with collaboration and communication as opposed to specific learning objectives or better conceptual understanding of content. In fact, some teachers were more concerned with their lessons being "fun" and "engaging" than they were on the content being discussed. They liked that iSTEM Education lessons that they had observed seemed fun and engaging for kids, so that was their primary reason for using them. Finally, while some teachers included some elements of engineering practices in their lessons and descriptions of iSTEM Education, most were underdeveloped. For example, the idea of making models and prototypes was the primary way of including engineering in a lesson. The idea was that as long as students were making building or making a model, they were engaging in engineering. Teachers had some 
understanding of what engineering entails but it was surface level and not necessarily representative of what engineers actually do.

\section{What do the teachers see as the benefits of students learning about STEM (outcomes)?}

Overall, teachers had very little to share regarding their thoughts on how iSTEM Education would be beneficial for their students. Most of them expressed they had heard about it and felt it was important but just didn't feel like they knew enough about it to really have much of an opinion beyond their surface level understanding of iSTEM Education. However, teachers tended to somewhat agree on the idea of there being academic benefits to students learning about and participating in iSTEM Education. Teachers also expressed that engaging in iSTEM Education enhanced retention. Teachers discussed how student engagement in iSTEM Education aided students in retaining information that they would be able to recall and apply later, be it later that school year or more long-term such as later in life. Teachers focused on potential jobs that might require skills promoted in iSTEM Education. For example, teachers expressed that iSTEM Education helps students become well-rounded or well-versed in multiple areas, making them capable of doing more than one thing. Teachers felt this was an important skill-set for students to have, to be good at more than one thing, because jobs now and in the future will demand that capability.

Last, some teachers felt a benefit to teaching iSTEM Education was because it was more engaging for students and therefore aided in behavior management. Teachers shared how they had students who had difficulty sitting still or behaving through more traditional methods of teaching but using more "STEM-based" lessons helped these students to be more engaged and produce better quality work.

\section{What is the nature and scope of teachers' integration of STEM disciplines?}

When it comes to integration, the number one area of concern for teachers was math. Teachers expressed that they felt math was the most difficult subject to truly integrate and struggled to figure out how to do so in their classrooms. Some felt like math was perhaps one of those subjects that had times when the concepts just needed to be taught separately, such as memorizing multiplication facts. Some teachers shared they would have counting or numbers involved in a math lesson, but there really weren't any explicit math concepts being taught.

Considering the Six Essential Features of Effective STEM Integration (Johnson et al., 2015), teachers in this study were primarily focused on feature three and feature six. Feature three indicated that effective STEM integration provides opportunities for students to make and learn from mistakes. Teachers in this study indicated they desired for their students to be able to make mistakes and tried to create a classroom environment that was conducive for students to take risks in their learning. Feature six emphasizes teamwork and collaboration, which many teachers emphasized as being an important reason for teaching iSTEM lessons.

Many teachers commented that they don't specifically teach iSTEM Education on a regular basis because they are not in a school or district where iSTEM Education is a particular focus. Because of this, they say they don't really have much in the way of professional development offerings and therefore lack the knowledge and skills they need to be able to integrate and teach iSTEM Education. All teachers commented on their focus of integrating reading and writing in everything they teach. While there was nearly universal agreement that subjects should not be taught in isolation, the degree to which integration should take place and what subjects should be integrated was unclear.

Finally, teachers revealed that very little time was devoted to iSTEM education in a typical school day. Some teachers had separate STEM times during the day or after school clubs that focused on iSTEM Education. However, most teachers did not teach iSTEM Education consistently or as a normal part of their typical school day. 
What instructional Designs, supports, and adjustments to the learning environment do teachers utilize when integrating STEM?

When it comes to iSTEM Education supports, teachers relied heavily on the internet and technological applications. Websites such as Pinterest and Teachers Pay Teachers were cited by all teacher participants as places they go to find iSTEM Education lessons. Additionally, applications such as Google Apps and Twitter were cited as iSTEM Education supports as well.

Aside from the technology supports for iSTEM Education teachers also indicated they relied heavily on teachers in their own building for support. Colleagues in their building who are either grade level partners, other classroom teachers in their building, or specialist teachers were all referenced as sources for iSTEM Education supports from participating teachers. No teachers mentioned having any iSTEM Education specific professional development, materials, or resources provided for them by their district for iSTEM Education. Teachers lack access to quality iSTEM Education specific resources and when they did find some they felt was worthwhile, they had to take it upon themselves to attain it (i.e. pay for it out of their own pocket, spend their free time at home working on a grant to get materials, etc.).

Considering the elementary teachers' unique opportunity to integrate (Becker \& Park, 2011), a surprising finding of this study is that teachers' lessons were primarily one subject only and many lacked components such as standards and objectives. While this may be an artifact of the shorthand of 'lesson plans', nonetheless the majority of lessons fell into the category of "No Integration" within Davison and colleagues' framework (1995). While it appears this is somewhat related to how teachers conceptualize STEM, it might also reflect lack of knowledge for how to integrate, or constraints of their mandated curriculum.

\section{Implications}

The results of this study illustrate that there is much work to be done in helping teachers create quality iSTEM Education lesson plans that integrate in a way that is reflective of the Essential Features of Effective iSTEM Education Integration. Despite highlighting teachers' enthusiasm and interest in iSTEM, the examples presented in this study revealed a multitude of common difficulties elementary teachers faced regarding their conceptualization and implementation of iSTEM Education. These common difficulties have implications for the design of professional development opportunities for elementary teachers in iSTEM Education in that they help to address the urgency to understand the obstacles educators face when creating and conducting integrated STEM experiences (Shernoff et al., 2017). I have identified the common elementary teacher difficulties when attempting to integrate iSTEM Education along with specific recommendations for professional development in Table 1. 
Table 1.

Teacher Difficulties Identified and Recommendations for Professional Development

\begin{abstract}
Identified Common Teacher Difficulties
Teachers have general ideas regarding their role when teaching iSTEM Education, but these ideas are underdeveloped.

Teachers struggle to decide what is or should be taught in iSTEM Education and get stuck on the subjects represented in the STEM acronym.

Teachers struggle with determining what iSTEM Education looks like at the elementary level.

Teachers saw technology in iSTEM Education primarily as using electronic gadgets.
\end{abstract}

Teachers saw iSTEM Education as something targeted primarily for gifted students or those who were good at math.

Teachers struggled to define iSTEM Education beyond knowing the subjects represented in the STEM acronym. Teachers expressed their primary goal for iSTEM Education lessons was for problem-solving.

Teachers use iSTEM lessons as 'ice breakers' or for team building activities. Not focused on mastery of content or skills.

Teachers had some idea about what engineering is in general but lacked knowledge on what it would look like at the elementary level.

Teachers struggled to understand the benefits of iSTEM Education beyond future job skills and behavior management.

Teachers struggled with integrating subjects, particularly math, beyond surface level and nearly all expressed great desire to have professional development in integration.

Teachers struggled to identify quality resources for teaching iSTEM Education lessons and depended on websites such as Pinterest and Teachers Pay Teachers.

Teachers struggled with the idea of creating their own iSTEM Education lesson plans but expressed the desire to learn.

Teachers struggled to find professional development in elementary iSTEM Education as their schools and/or districts did not have a STEM focus.

\section{Recommendations for Professional Development}

Teachers need to engage in discussions and view videos of iSTEM Education in action to get a more clear idea of the teacher and student roles in iSTEM Education.

Teachers need to engage in activities and discussions aimed at illustrating what should be taught within iSTEM Education.

Teachers need to see images of iSTEM Education and at the elementary level through videos and sample lesson plans.

Teachers need to consider different ways technology can be integrated to not only enhance other subjects but to build technological skills specifically.

Teachers need to engage in activities and discussions that challenge this misconception to develop an understanding of STEM for all.

Teachers need to examine, compare, contrast, and develop their own definitions of iSTEM Education.

Teachers need to engage in activities and discussions on problem-solving strategies and to identify the various types and how they work in engineering.

Teachers need to engage in lesson plan analysis tasks to aid in learning how to develop iSTEM lesson plans that have a purpose and are focused on content.

Teachers need to engage in an analysis of various engineering design cycles and see images of what engineering what look like at the elementary level.

Teachers need to engage in activities where they are exposed to positive and negative rationales for iSTEM Education to allow them to develop an understanding of the benefits of iSTEM Education.

Teachers need to engage in activities and discussion focused on integration methods of various subjects in iSTEM Education, particularly math.

Teacher need to critique lessons and units of iSTEM Education to learn how to determine quality iSTEM Education lessons.

Teachers need to create iSTEM Education lessons and units with guidance that are applicable to the grade level they teach.

Teachers need an online course so all teachers, regardless of location, have access to iSTEM Education professional development.

Based on the common teacher difficulties identified above, professional development providers will have a clearer understanding of the unique professional development needs for elementary teachers in iSTEM Education. Furthermore, the identification of these common difficulties may inform the design of new professional development programs and experiences that specifically address and support the needs of elementary teachers in their pursuit towards teaching quality iSTEM Education in their classrooms. These professional development experiences are vital if elementary teachers are to be expected to teach iSTEM Education (NRC, 2011). 
To move the field forward, future studies should focus on the way in which elementary teachers integrate content in their teaching practice in general, as well as regarding iSTEM Education specifically. Next, future studies should attempt to work towards identifying best practices and methodologies for teaching iSTEM Education at the elementary level. Finally, future studies should investigate the effectiveness of the professional development experiences provided for elementary teachers in iSTEM Education.

\section{References}

Ansberry, K., \& Morgan, E. R. (2010). Picture-perfect science lessons: Using children's books to guide inquiry. NSTA Press.

Becker, K., \& Park, K. (2011). Effects of integrative approaches among science, technology, engineering, and mathematics (STEM) subjects on students' learning: A preliminary meta-analysis. Journal of STEM Education: Innovations and Research, 12(5/6), 23.

Creswell, J. W. (2013). Research design: Qualitative, quantitative, and mixed methods approaches. Sage publications.

Davison, D. M., Miller, K. W., \& Metheny, D. L. (1995). What does integration of science and mathematics really mean? School Science and Mathematics, 95(5), 226-230.

Fulp, S. (2002). The status of elementary school science teaching. Chapel Hill, NC: Horizon Research. Retreived from http://www.horizon-research.com/horizonresearchwp/wp-content/uploads/2013/04/elem science.pdf

Hanover Research (2012) Best Practices in Elementary STEM Programs. Washington D.C.: Retreived from http://school.elps.k12.mi.us/ad_hoc_mms/committee_recommendation/4.pdf

Heil, D., Pearson, G., \& Burger, S. (2013). Understanding Integrated STEM Education: Report on a National Study. Presentation at the 120th ASEE Annual Conference and Exposition, Atlanta, GA.

Honey, M., Pearson, G., \& Schweingruber, H. (Eds.). (2014). STEM Integration in K-12 Education: Status, Prospects, and an Agenda for Research. National Academies Press.

Johnson, C. C., \& Sondergeld, T. A. (2015). Need for Professional Development to Change Practice. STEM Road Map: A Framework for Integrated STEM Education.

Johnson, C. C., Peters-Burton, E. E., \& Moore, T. J. (Eds.). (2015). STEM Road Map: A Framework for Integrated STEM Education. Routledge.

Ma, L. (1999). “Teachers' Subject Matter Knowledge: Profound Understanding Of Fundamental Mathematics." Knowing and teaching elementary mathematics: Teachers' understanding of fundamental mathematics in China and the United States. Mahwah, NJ: Lawrence Erlbaum Associates.

Magnusson, S. K., \& Krajcik, J. J. \& Borko, H.(1999). Nature, sources and development of pedagogical content knowledge for science teaching. Gess-Newsome \& Lederman (Eds.), Examining Pedagogical Content Knowledge: The Construct and Its Implications for Science Education. Dordrecht: Kluwer Academic Publishers.

Means, B., Confrey, J., House, A., \& Bhanot, R. (2008). STEM high schools: Specialized science technology engineering and mathematics secondary schools in the US. SRI International, 25.

Nadelson, L. S., Callahan, J., Pyke, P., Hay, A., Dance, M., \& Pfiester, J. (2013). Teacher STEM perception and preparation: Inquiry-based STEM professional development for elementary teachers. The Journal of Educational Research, 106(2), 157-168.

Nathan, M. J., Srisurichan, R., Walkington, C., Wolfgram, M., Williams, C., \& Alibali, M. W. (2013). Building cohesion across representations: A mechanism for STEM integration. Journal of Engineering Education, 102(1), 77-116. 
National Research Council. (2011). A framework for $k$-12 science education practices, cross-cutting concepts, and core ideas. Washington, DC: National Academies Press.

President's Council of Advisors on Science and Technology (US). (2010).Prepare and Inspire: K-12 Education in Science, Technology, Engineering, and Math (STEM) for America's Future: Executive Report. Executive Office of the President, President's Council of Advisors on Science and Technology.

Richardson, V. (1996). The role of attitudes and beliefs in learning to teach. Handbook of research on teacher education. Macmillan Library Reference USA, Simon \& Schuster Macmillan, 1633 Broadway, New York, NY 10019.

Ring, E. A., Dare, E. A., Crotty, E. A., \& Roehrig, G. H. (2017). The evolution of teacher conceptions of STEM education throughout an intensive professional development experience. Journal of Science Teacher Education, 28(5), 444-467.

Sanders, M. (2009). STEM, STEM Education, stemmania. The Technology Teacher, 68(4), 20-26.

Sias, C. M., Nadelson, L. S., Juth, S. M., \& Seifert, A. L. (2016). The best laid plans: Educational innovation in elementary teacher generated integrated STEM lesson plans. The Journal of Educational Research, 1-12.

Shernoff, D. J., Sinha, S., Bressler, D. M., \& Ginsburg, L. (2017). Assessing teacher education and professional development needs for the implementation of integrated approaches to STEM education. International Journal of STEM Education, 4(1), 13.

Stake, R. E. (1995). The art of case study research. Sage.

Trygstad, P. J. (2013). 2012 National Survey of Science and Mathematics Education: Status of elementary school science. Chapel Hill, NC: Horizon Research, Inc.

Wang, H. H., Moore, T. J., Roehrig, G. H., \& Park, M. S. (2011). STEM integration: Teacher perceptions and practice. Journal of Pre-College Engineering Education Research (J-PEER), 1(2), 2.

Williams, J. (2011). STEM education: Proceed with caution. Design and Technology Education: An International Journal, 16(1). 


\section{APPENDIX A \\ Teacher Vignette}

\section{Thematic Integration - Laura}

Laura definedSTEMEducation as “...trying to combine science, technologyengineering and math skills and concepts... and [students] learn how they are associated together and that they are introducedin a hands-on experience instead of just a teacher lecturing about the concepts." Laura continued to comment about how she believedengineeringwas "how thingscometogether" and shedescribedscienceassomethingthat "justhappens."

Laura described her goals for students when teaching a STEM lesson as primarily a way of keeping her students busy. She explained that she tries to keep her students "doing" all day. Laura describes another general goal for her classroom is trying to include technology because students do all of their tests with technology when they get to high school. Laura speaks about instructional technology use as something she and her grade level teacher colleagues try to incorporate more of, particularly iPads. She also commented that "...it [STEM] is something that was put on the backburner for reading and math..."

The biggest benefit Laura described for having students learn about STEM, was getting students to see how subjects went together. For example,Laura says "I thinkit is important that kidsseehow they [subjects], how thosepiecesareintertwined together. Thatwehavetohaveanunderstandingofallofthosetodoanyofthosethings well." Shealso feltSTEM would help herstudentstofeelokay about making mistakesand to explain their thinking.

Laura submitted a lesson called "Pumpkins Galore" which she created herself that she was not required to teach. The objective of the lesson was for students "...to expose students to the different parts of a pumpkin, practice counting, and to explore different ways to use a pumpkin for fun". Throughout the two-session lesson, students use pumpkins in a variety of activities to make predictions. Students record predictions and noticings on height, weight, color, buoyancy, etc. Students then guess and count the number of seeds in the pumpkin. An art extension is included as an option where students are able to paint or carve their pumpkin. Neither formative nor summative assessments are included in the lesson plan. Additionally, standards being addressed were not included in this lesson plan. The lesson Laura submitted was classified as Thematic Integration as her lesson was focused on pumpkins and all activities revolved around the theme. Davison, Miller, and Methany (1995) described thematic integration as a way of integrating many subjects around a central topic or theme. Laura shared that she tried to structure her STEM lessons in a way that went along with whatever theme or time of the year was taking place, such as the pumpkin lesson because it was around Halloween. When asked how she came up with the idea for the lesson, Laura said that shealwayscarves pumpkinswith herclassand that shethought thislesson wouldgo beyond "play." Laura continued to describe how her STEM lessons were rarely ever planned out and that she just tries to connect ideas back to science or math as they come up. She shared her frustration with teaching science and that she has no curriculum or materials to use aside from a weekly reader she gets from a school book publishing company. She explains "I don't feel like I am equipped well enough to put all of those pieces together regularly...in our building it [teaching science] is pretty much whatever the teacher chooses to teach and when they teach and how they teach it." Laura shared that because she doesn't have materials provided by her district, she relies heavily on Teachers Pay Teachers and other internet sites to find STEM lessons and ideas. Laura shared that her STEM lessons generally have an art or craft project included because that is what she likes.Laura stated that she had a little bit of professional development in science but none specifically in STEM Education. She shared that she desires professional development on integration and how to make iSTEM Education lesson plans. Laura lamented that while she desires to know more about STEM Education, her building doesn't focus much on STEM as it has taken a "backseat" to reading and math. 


\section{No Integration-Mary}

Mary defined STEM Education as “... learning how to explore and build on things... create new things...taking a look at how things work... discovering things to learn concepts...a hands-on exploratory approach to learning...trying to solve a problem that has more than one answer..." Mary continued to describe how she felt engineering was a "creation process" and that it was different from science because science is the "core concepts" while engineering is taking those concepts and "creating something to solve a problem."

Mary's biggest goal for students when teaching iSTEM Education was to get students to be independent and to be okay with making mistakes. She described problem- solving as the biggest benefit she sees in teaching iSTEM Education. She stated, "I think it is important to teach them [students] that this is how you're going to have to figure something out because there isn't always going to be an answer." Mary submitted a lesson plan called "Properties of Matter" which she borrowed from a colleague who got it from Teachers Pay Teachers. The objective for students stated, "Students will describe and sort objects based on color, shape, size, and texture." This lesson was structured as individual thirty-minute lessons that would span for six days. Activities included a nature walk, button sort, class discussion on matter, cracker sort, and the construction of a "Nature Friend" (a craft project using items found in nature to build a "friend" using a Styrofoam cup as the body).

The lesson Mary submitted was classified by the researcher as No Integration. The topic of Mary's lesson is properties of matter, and all activities in the lesson are focused on the subject of science. Students participate in a variety of seemingly disconnected activities, and the final product of the lesson is a "Nature Friend" that is created out of a Styrofoam cup and items students found during a nature walk at the beginning of the lesson. When Mary was asked about integrating STEM subjects in the interview, she stated "...I don't want to say we have dropped out math...we talk about math within our STEM lessons but... I wouldn't say it is $100 \%$...they all kind of work together...not all of our lessons include all four of those things..."

Mary described the way she typically structures her STEM lessons as lasting about thirty minutes every afternoon for science and her lessons focused on students explaining and exploring. She continued that students typically are working together and "...have some sort of hands-on materials that they are manipulating and working with to create some sort of solution..."

Mary shared that she feels she has a wonderful support system when it comes to teaching STEM Education and specifically cited her grade level partner and other teachers in her building. She also mentioned that her building has different resources available for STEM Education as they have a membership to the National Science Teachers Association as well as a grant from the Missouri Partnership for Education Renewal (MPER). However, she commented that she does a lot of internet research and frequently uses Pinterest to find STEM lessons. Mary shared that while she would like to have professional development on teaching iSTEM Education, she was unsure as to how willing many of the other teachers in her building would be to try something new. 


\section{Content Specific Integration- Cassie}

Cassie defined STEM Education as "...trying to integrate science into as many things as possible... so maybe reading, writing, science all in one... the technology piece like iPads and maybe research...using as much of the iPads and devices..." Cassie continued to admit that she had no idea what the "T" in STEM meant and that she "didn't have a clue" as to what engineering would look like at the elementary level, but she thinks it would have something to do with designing and building.

Cassie's main goal for teaching iSTEM Education is influenced by her school's focus on integrating the expressive arts. She explains "....we are the arts integration school, so everything we do we try to hit as many areas as possible using art, music, drama, dance, even technology... our fine arts objectives or our learning objectives are the main things..." Cassie describes her view on the benefits of students learning about STEM as a way to promote higher-level thinking. She states "...it [STEM] is requiring them to think not just at the base level of input knowledge and just recall...it is all at the higher level of thinking. It really digs in and makes them really think." Cassie also commented on how she believes that STEM Education can aid in encouraging students to have better behavior and be more productive.

Cassie submitted a lesson called "Lunes and Leaf Rubbings" which she got from a colleague who left their school many years ago. She was not aware of the original source, and she was not required to teach it. The objective of the lesson was "Students will experiment with writing lune poems (a form of Haiku poetry) based upon items found in nature." The lesson spanned three sessions and connections to state standards included fine arts and communication arts standards.

The lesson Cassie submitted was classified as Content Specific Integration. Content Specific Integration is when a lesson includes one objective from one subject and one objective from another. Davison, Miller, and Methany (1995) describe Content Specific Integration as using one objective from both math and science. However, in this study, a lesson could be categorized as Content Specific Integration if there were one objective from any two subjects included. In Cassie's case, her lesson included an objective from writing and another from art. When asked to describe her reasons for integrating the arts into her lesson, she stated "...we are the arts integration school so everything we do we try to hit as many areas as possible using art, music, drama, dance, even technology... we really kind of look at it like a big umbrella...” Additionally, Cassie described the difficulty she and others in her school experience when trying to integrate math into their art-focused curriculum because "math is so hard to integrate." Cassie emphasized that at her school science, technology and engineering are not a focus. She clarified that they do teach science but that it is not a focus for them.

Cassie described her typical lesson structure when teaching an iSTEM Education lesson as one that uses guided practice and "would definitely include a movement activity." Her lessons last about an hour and her job would be to model her expectations, so students knew what she expected of them. In the lesson Cassie submitted, she described how movement was integrated into her STEM lesson when her students go outside to observe leaves. She continues “...they get to basically imitate the leaves with their body. So they dance around, they float around, and they twirl. So they are basically observing the leaves and then doing things with their bodies to imitate that ..." Cassie also describes how she allows her students who are shy to use finger puppets to help them explain their thinking to their peers.

Cassie commented on how she feels she has a good amount of support for integrating and feels certain that if she went seeking for more STEM support that she would be able to get it. She cited her building art team (specialist teachers in art, music, drama, and dance) as the main source for helping her with integration, as well as the other teachers in her building. She described how helpful her district's science and math coordinators are and that she felt if she asked them for assistance then they would be very good about providing it. 
Her instructional resources for STEM are basically their buildings access to Science A-Z and the math and science curriculum provided by her district. When it comes to her resources that aid in her integration strategies, she explained "...I use Pinterest...we use Pinterest a lot to find ways that we can integrate as much as possible..."

Cassie shared that she was a bit apprehensive about how her building would react to any iSTEM Education professional development because it just wasn't a focus for them. She explains “...I'm not knocking STEM, but... again I think it is important so obviously, we have a need for pd, but...it is not something I feel like our building would focus on." Cassie stressed that perhaps individual teachers might go out and find STEM professional development and she might be interested to see what it would look like at the elementary level, but she really felt that she and the teachers at her building are solely focused on what they are doing at their building, which is focusing on the arts. 


\section{Methodological Integration- Sidney}

Sidney defined STEM Education as "... taking science to a new more modern day level... the future careers and the future of our country and world is more based in science, technology, engineering, and mathematics...". She continues "...our kids are sadly too much in just rote memorization of basic scientific facts. So it is becoming more hands-on and real world applicable for solving problems within those fields." Sidney also described engineering as a building and design process and cited multiple careers where engineering design processes are used.

Sidney has many learning goals for her students when teaching a STEM lesson, but she comments on how her primary goals come from her state standards. She discusses the responsibility of public school teachers to stick close to their state standards. Her secondary goal, which she hits on multiple times throughout her phone interview, is focused on student retention. Sidney also has an overarching goal of getting students to be well-rounded and proficient at many different things. She sees this as both a goal and a benefit for having students learn STEM Education. Sidney focuses on the future needs of her students and how they will need to be "well-versed in multiple areas" to be good at most jobs. She describes the need for students to be problem solvers and to realize that students need to be able to create and implement their own ways to come up with a solution.

Sidney submitted a lesson plan called "Problem Solvers" which she adapted from a book called Even More Picture Perfect Science by Ansberry and Morgan (2010). Sidney was not required to teach this lesson. There were six different learning outcomes included in this lesson and five science and math Missouri Learning Standards. This lesson was structured as a 5E lesson that would span over five separate class periods, each lasting thirty to ninety minutes each day. A student assessment and modifications or accommodations were also included.

The lesson Sidney submitted was classified as Methodological Integration. Davison, Miller, and Methany (1995) essentially describe Methodological Integration as a method of integration that investigates issues, for example, in science and math using discovery, inquiry, and the learning cycle. There is a building of knowledge that occurs within the lesson as students progress. Sidney's lesson uses the 5E Learning Cycle (Engage, Explore, Explain, Extend, and Evaluate) and students are working to solve problems.

Sidney explained that her STEM lessons don't follow a typical structure, but she does have about two to three hours a week for teaching her "old-school" science lessons. Sidney utilizes Genius Hour and Makerspaces in both her classroom and her after-school club, while also using instant challenge task cards from Discovery Innovation. Sidney says her lesson structure depends on the activity. For example "...I do Makerspace in my classroom twice a week for about an hour each time... we started with task cards that are open ended... like create a robot...there is like 100 task cards that I got from our gifted teacher..." Sidney commented that she is trying to provide more opportunities for her students to engage in exploration and becoming a more student-centered educator.

Sidney stated that she didn't really feel like her district is providing her with any materials or resources to assist her with her STEM teaching as they aren't quite on board with STEM Education yet. Sidney remarked that her main source of STEM support comes from other teachers in her building, such as her grade level partners and the gifted teacher. Sidney described that she has taken the responsibility to write grants for money needed to purchase STEM materials and that she uses various internet resources such as Google and YouTube for lessons and ideas. When asked about the areas she desired more professional development, Sidney had a lot to say. She explained that she would like more professional development in developing lessons and how to find resources that are free or affordable. She discussed her understanding of the importance of STEM Education but said she just doesn't know how to get it done by herself. 


\section{Process Specific Integration- Kim}

Kim defined STEM Education as “... Science, Technology, Engineering and Math education...I am lucky enough to teach in an arts integrated school so STEM would be more science, technology, engineering, art, and math integrated...so pulling those subjects into all parts of teaching." Kim explained the difference between engineering and science as engineering being "the study of how things are built and how things are made and created." She explained that she felt engineering was an aspect of science but was more "process related."

Kim's goals for students when teaching STEM begins with the objective for the lesson and the content being taught. She explained that if she was teaching a social studies lesson, then her primary objective would be that students had correct social studies content information. She stated that if say, technology was the focus of the lesson and the content was secondary, then she would be looking for mastery of the technology skill. Kim shared she felt STEM Education was beneficial for students because it helped them to be "well-rounded." She commented on how technology is changing "minute by minute" and how students need to be able to change with it. She also felt problem-solving, and collaboration skills were important benefits of students participating in STEM Education. Kim also commented on how she believes some students are more successful in STEM Education than others. As an example, she cited a student in her class who is "gifted" and "math minded" but is not necessarily creative. She says "... he is creative, but he is not a visual artist. He is not a great singer, he is not a great actor, but he is great with math and numbers and really good at problem-solving...so that helps."

Kim submitted a lesson plan called "Towering Towers" which she got from a colleague "many years ago." Kim was unsure of where the lesson originated, but she was not required to teach it. The goal of the lesson stated "As a team, you must only use the given materials, to build a tower that will support a ping-pong ball. Points are given for originality, neatness, height, and cost of materials". This lesson would take place during a single class session. There were no standards or objectives included in the lesson.

Kim’s lesson was classified as Process Specific Integration. Davison, Miller, and Methany (1995) describe Process Specific Integration as an approach where students use real life activities to engage in science and math processes. Solving a problem is a part of process integration and Kim's lesson, while not exactly a real life problem, poses a problem for students to solve as a team. Students are expected to build a tower using only the materials provided and considering the cost of all materials used.

Kim explained the structure of her STEM lessons when she stated: “...depending on the lesson it is either, you know I will introduce the objective and then do a gradual release of content". She continued her description by saying she tends to incorporate a lot of technology into her teaching. She likes to use Schoology as a platform for paperless work and uses Google Apps, QR Codes, and other apps in her classroom as her students are all 1:1 with iPads. When asked how she integrates science, technology, engineering and math, Kim stated that she hadn't taught science in about ten years as her school departmentalizes. She commented she tries to integrate math but "Math is one of the hardest subjects to use art integration." She also commented on how she utilized other teachers, district coordinators, and the internet for help when developing her STEM lessons. Kim desired professional development in integration, specifically with the arts as she is at an arts school. She wants to be able to integrate STEM with the arts but would like it not to be "a chore or something extra...just make it kind of natural." 